\title{
Antropologia e educação: um campo e muitos caminhos
}

Neusa Maria Mendes de Gusmão

Universidade Estadual de Campinas

\section{Resumo}

0 presente texto discute interação entre coisas diversas, vale dizer que não são iguais ou de mesma natureza. É disso que se trata quando pensamos em relações possíveis entre dois campos de conhecimento: a antropologia e a educação. Campos que diferem em seus princípios e também em seus pressupostos centrais, cujo movimento de intercomunicação e troca supõe a crítica constante e a revisão permanente dos próprios passos. Por esta razão, falar em diálogo entre campos diversos de conhecimento é também falar de possíveis conflitos e riscos. É falar de um contexto tensional que desafia o fazer antropológico, sua prática e seu suporte teórico, quando transita como campo de conhecimento a outro campo, numa região de fronteira. 0 objetivo é o de pensar as possibilidades de uma antropologia da educação compreensiva e crítica que se encontra em construção no Brasil hoje.

Palavras-chave: Antropologia da educação. Etnografia. Educação e diversidade. História 


\section{Anthropology and education: one field and many paths}

This paper discusses the interaction between different things that are neither equal nor similar in nature. That is the case when we think of possible relations among two fields of knowledge: Anthropology and Education. Fields that differ in their principles and in their central assumptions, whose movement of intercommunication and exchange presupposes constant criticism as well as a continuing review of one's own steps. For this reason, talking about dialogue between diverse fields of knowledge is also talking about potential conflicts and risks. It is speaking of a tensional context that challenges anthropological work, its practice and theoretical support, when it moves in a border region between one and another field of knowledge. The goal is to think about the possibilities of a comprehensive and critical Anthropology of Education, under construction in Brazil today.

Keywords: Anthropology of Education. Ethnography. Education and Diversity. History.

\section{Antropología y educación: un campo y muchos caminos}

Este artículo analiza la interacción entre cosas variadas, es decir, que no son iguales o de la misma naturaleza. Es aquello que se trata cuando pensamos acerca de las posibles relaciones entre las dos áreas de conocimiento: Antropología y Educación. Los campos que difieren en sus principios y en sus supuestos centrales, cuyo movimiento de intercomunicación de cambio y asumir la crítica constante y la revisión permanente de los propios pasos. Por esta razón, el diálogo entre los diferentes campos del saber hablar es también hablar de los posibles conflictos y riesgos. Es un contexto tensional que desafía el trabajo antropológico, su práctica y su soporte teórico cuando se transita de un campo de conocimiento a otro campo en una región fronteriza. El objetivo es reflexionar sobre las posibilidades de una antropología de la educación y la revisión completa que se encuentra en construcción en el Brasil de hoy.

Palabras-clave: Antropología de la educación. Etnografía. Educación y diversidad. Historia. 


\section{Introdução}

A antropologia é uma ciência do "fazer-fazendo", que se constrói pela crítica constante de seus próprios passos, uma ciência que "aprende-e-ensina", ao mesmo tempo que "ensina-e-aprende". Por essa razão coloca-se como mais valia no campo educacional, desafiada pela ruptura entre ensino e aprendizagem, seja dos que ensinam, seja dos que aprendem. (Gusmão, 2010, p. 262)

A palavra interface que nomina este dossiê se faz presente em minhas preocupações com a ciência antropológica desde muito tempo (Gusmão, 1997). Tal palavra tem por significado estabelecer um campo de trocas, de intercomunicação ou de ação mútua, como informa qualquer dicionário. A base desses processos está dada pela interação entre coisas diversas, vale dizer que não são iguais ou de mesma natureza. É disso que se trata quando pensamos em relações possíveis entre dois campos de conhecimento: a antropologia e a educação. Campos que diferem em seus princípios e também em seus pressupostos centrais, cujo movimento de intercomunicação e troca supõe a crítica constante e a revisão permanente dos próprios passos. Por esta razão, falar em diálogo entre campos diversos de conhecimento é também falar de possíveis conflitos e riscos. É falar de um contexto tensional que desafia o fazer antropológico, sua prática e seu suporte teórico, quando transita como campo de conhecimento a outro, numa região de fronteira.

0 desafio de "fazer-fazendo", de "aprender e ensinar", enquanto "ensina e aprende" consiste em esforços de "re-unir" teoria e prática, ensino e aprendizagem, quando se fala em educação. Não qualquer educação, mas educação como processo que, inerente à condição humana, transfigura-se numa condição específica e escolarizada nas chamadas sociedades de classe sociedades de marcada hierarquia e desigualdades, como é o caso da sociedade brasileira. Contudo, processos educativos ocorrem em meio à vida vivida, como parte das relações humanas que não se restringem ao espaço da escola, como é suposto em sociedades como a nossa. E, nesse sentido, é que se podem pensar as possibilidades de uma antropologia da educação ou as relações entre antropologia e educação.

Em outro momento (Gusmão, 1997), trabalhando com tais supostos, cito Carlos Rodrigues Brandão quando diz que, em toda e qualquer sociedade humana, existe aprendizagem inerente à prática social e da vida. Segundo ele, a educação existe independentemente de se ter ou não uma rigorosa divisão de trabalho entre sujeitos desiguais, ou ainda, mesmo ali, onde possa ou não, existir escola. A escola, diz o autor, não é o único lugar em que a educação acontece. Assim, a educação 
existe, também, em sociedades hierarquicamente divididas em classes e, nestas, é pensada como saber que surge como especialidade que separa sujeitos sociais. Um saber que separa tudo e todos e estabelece um alguém que ensina diferente daquele que aprende. Separa ensino e aprendizagem. Em suas palavras, é nesta medida que se cria a pedagogia que isola a educação que se pratica na escola dos processos educativos mais abrangentes e inerentes à vida social. É aqui que a escola se faz lócus de obrigações e deveres, que se distancia dos sujeitos e daquilo que os orienta no tecido social, ou seja, sua cultura. Tal problemática nos autoriza a pensar as possibilidades de uma antropologia da educação compreensiva e crítica que se encontra em construção no Brasil hoje. Porém, este é um dos muitos caminhos possíveis de sua construção, o qual se centra na questão do ensino e da aprendizagem compreendida, aqui, como composta por elementos de constituição de nós mesmos como sujeitos culturais e históricos. Nesse sentido, a educação é compreendida como partilha, comunicação e troca, pressuposto da aprendizagem e componente fundamental da cultura. Entende-se que não é possível tratar da educação sem falar em cultura e não se pode falar em cultura sem considerar a educação. Assim, colocar a dialogar a antropologia e seu método, o professor e sua prática no campo educacional implica, para um e para o outro, ter que reconhecer a heterogeneidade do social, com múltiplas e diversas experiências. Múltiplas e diversas culturas. Implica o assumir da teoria e da prática como elementos inseparáveis na construção do conhecimento, naquilo que é o método antropológico e a centralidade de sua maior ferramenta: a "cultura".

Por isso mesmo, segundo Ricardo Vieira (1995; 1999), a comparação e a reflexividade são suportes do processo que nos permite chegar à antropologia da educação e compreendê-la como contributo para a formação docente, de qualquer docente, na antropologia e fora dela. 0 pressuposto é que a antropologia faz parte de um corpus de conhecimento que difere do corpus que sustenta a educação. Nesta, a forte presença da psicologia tem levado o processo educativo a centrarse na ação educativa mais do que no campo educacional ${ }^{1}$. E isto faz toda diferença.

Faz diferença também o fato de que o campo científico não é plenamente autônomo e deve sua forma e legitimidade a uma rede de interesses e de poder. Rede esta que regula e define o conhecimento científico, de modos a dizer o que é conhecimento e o que não é. Define também os temas em voga a cada momento, as regras das agências financiadoras, o interesse das instituições de ensino e

1. Ação Educativa é de ordem prática e mais prescritiva. Objetiva, por meio da socialização, interiorizar sentimentos, hábitos, valores inerentes à ordem social. Diz respeito às teorias positivistas de sociedade. Campo Educacional busca uma visão compreensiva da realidade social, mais interpretativa, ordenada pelo campo político e pelas relações de poder. Tem por paradigma a noção de conflito. Considera a dinamicidade da produção e da reprodução do mundo social. Ver a respeito: Lovisolo (1984). 
pesquisa, assim por diante, por meio das quais se efetiva e se consolida a ciência que se pratica. E, nesse sentido, afeta as possibilidades de constituição de um novo campo ou de um campo que se recompõe com novas vertentes, neste caso, a antropologia da educação contemporânea.

Do problema assim proposto e entre as possíveis construções desse debate, recorto a abordagem dessa temática por dois ângulos, quais sejam: a natureza da relação antropologia e educação e o campo científico que define, a cada momento específico, o que é ciência e o que não é. Em jogo as relações de poder no âmbito do conhecimento e o trânsito de um campo em construção ou reconstrução ${ }^{2}$ a "antropologia da educação" - para um campo já constituído que se imagina consolidado - a "educação". 0 contexto é, então, teórico e político, exigindo pensar que toda e qualquer ciência seja sempre movimento e, neste caso, pensar tais relações a partir de um lugar específico: as "ciências sociais".

\section{Antropologia e educação: desafios do método}

A antropologia da educação ou antropologia e educação ${ }^{3}$ coloca como exigência ter presente o lugar do qual se fala, neste caso, as ciências sociais para, a partir da antropologia, abordar a educação. Neste caso, como já foi dito, o ponto de partida importa para definir a natureza das relações entre campos diversos. 0 olhar moldado pelas ciências sociais é um e o olhar a antropologia desde a educação certamente obedece a outros parâmetros, posto, como diz Fonseca (1999), ao referir-se ao método antropológico, que este não é tão aberto como se imagina. Segundo a autora,

Quando estudantes de educação (ou comunicação ou medicina etc.) soltam as amarras de suas tradições disciplinares e se atiram na direção da antropologia sem preparação adequada, podem, em vez de realizar uma costura interdisciplinar, cair no vazio - um território nem lá, nem cá, onde o que mais floresce é o senso comum da cultura do pesquisador. (Fonseca, 1999, p. 62)

Assim, para Fonseca é preciso ter em mente que, ao fazer parte das ciências sociais, a antropologia e seu método não se fazem sem amarras teóricas

2. Reconstrução em razão de não ser a questão exatamente nova, mas de recompor o campo com novos parâmetros colocados por demandas do tempo atual.

3. Assumo aqui que há uma antropologia da educação sendo feita no Brasil para seguir uma tendência mais comum em toda a América Latina e, assim, fortalecer esse campo na academia e também junto às agências de fomento. 
consistentes e situadas. Portanto, nem "tão "aberta", já que a pertença ao universo das ciências sociais exige "o enquadramento social (político, histórico) do comportamento humano" (1999, p. 62). Nessa medida, é preciso colocar as "comunidades da prática" às claras no interior da coletividade acadêmica e científica que nos rege e suas propostas em termos dessa interface. Aqui, os muitos caminhos de um campo em construção desafiam aqueles que "fazem-fazendo" e instauram modos de "ensinar e aprender", ao mesmo tempo que aprendem e ensinam que há uma antropologia da educação sendo feita no Brasil de hoje, demarcada pelo trabalho de campo e pela etnografia. Nesse sentido, ou seja, pelo seu método, a antropologia se faz presente em diferentes áreas de conhecimento e, particularmente na educação em razão,

das exigências que advêm das políticas nacionais de educação (LDB; PCN) e das políticas de diversidade (Lei n. ${ }^{0} 10.639 / 03$ e n. ${ }^{0} 11.645 / 08$ [entre outras]) que hoje regem o fazer educativo e impõem novas exigências no âmbito das práticas pedagógicas, com implicações na formação de professores e educadores brasileiros. (Gusmão, 2010, p. 259)

Contudo, a questão da diversidade hoje é moda que se espraia e se multiplica como pano de fundo em que se movem diferentes interesses e concepções e ela é particularmente intensa no campo da educação, tanto quanto no campo político de um país como o nosso. Assim, é por conta de leis, decretos e do próprio movimento social que surgem demandas específicas por educação, ou seja, a título de exemplo, a chamada "educação diferenciada" - quilombola, indígena, sem terra, entre outras. Com isso, a questão da diversidade atinge as ciências sociais em seu escopo mais tradicional e ressalta as possibilidades do campo antropológico em detrimento dos outros campos que a conformam, como a sociologia e a política. Contudo, cabe lembrar, como disse Pierre Sanchis (2006), a respeito dos problemas da antropologia, que, se podemos detectar uma multiplicação desse campo, há também afunilamento dos objetivos de pesquisa e um empobrecimento que afeta alunos e professores na universidade, seja em razão de novas relações entre professores e alunos, seja por conta de temas que ainda não encontram respaldo acadêmico e, por conseguinte, não constituem temas em melhores condições de atendimento por parte das instituições de fomento. Pode-se dizer que isso tudo afeta as possibilidades de um novo campo de conhecimento - a "antropologia da educação" -, como afeta as condições do trabalho de campo e da prática etnográfica. Dessa forma, muitas vezes, ter a educação como tema de estudo/investigação coloca em desprestígio tanto o interesse do pesquisador que desde a antropologia busca olhar a educação, como enfraquece quem, desde esse 
campo, assume a etnografia sem com ela assumir os pressupostos teóricos da ciência antropológica. Como já dizia Ana Lucia Valente (1996, p. 63),

Tudo indica que a matriz teórica da qual partimos, enquanto estudiosos das Ciências Sociais, é o nó górdio da questão. Em outras palavras, a partir dela pode-se promover, de fato, um ensaio de diferenciação [entre Antropologia e Educação]. É ela que define preocupações, forma e conteúdo das análises [...]

Assim, a antropologia como ciência busca avaliar as diferenças e proporcionar alternativas de intervenção sobre a realidade de modo a não negar as diferenças, como tem sido comum na história ocidental e nos processos educativos que the são próprios. Nesse sentido, as relações sociais entre diferentes são entendidas como relações de poder socialmente construídas em sociedades como a nossa. São eles, os processos de:

- homogeneização lobjetivo de agentes e agências que operam o tecido social e implicam um campo de poder)

- contradição (socialização/sociabilidades construídas nas relações sociais entre sujeitos diversos e na gestão dos interesses coletivos)

- conflito (de classe e de outra natureza, tais como raça, cor, gênero, etc...)

Portanto, falar de antropologia e de seus métodos exige pensá-la como uma ciência situada, que caminhou do "outro" como diferente ao "outro" que compõe a alteridade do mundo moderno no jogo entre homogeneização, contradição e conflito. Esse caminhar só foi possível pelo estranhamento do social (de longe e de pertol e pelo modo específico de proceder na construção de um conhecimento do "outro", a que chamamos etnografia e sua constituição no tempo.

Num texto bastante conhecido, François Laplantine (2007) afirma que "vale a pena especificar bem o significado" do que seja Etnologia, Antropologia e Etnografia. Diz ele:

Estabeleçamos, como Lévi-Strauss, que a etnografia, a etnologia e a antropologia constituem os três momentos de uma mesma abordagem. A etnografia é a coleta direta, e a mais minuciosa possível, dos fenômenos que observamos, por uma impregnação duradoura e contínua e um processo que se realiza por aproximações sucessivas. Esses fenômenos podem ser recolhidos tomando-se notas, mas também por gravação sonora, fotográfica ou cinematográfica. A etnologia consiste em um primeiro nível de abstração; analisando os materiais colhidos, fazer aparecer a lógica específica da sociedade que se estuda. A antropologia, finalmente, consiste em um segundo nível de inteligibilidade: construir modelos que permitam comparar sociedades entre si. (Laplantine, 2007, p. 25, nota 7) 
Nesse sentido, a ciência antropológica é essencialmente comparativa. Razão pela qual, falar de pesquisa etnográfica é falar das possibilidades e limites do encontro etnográfico e de sua realidade histórica entre dois momentos particulares: o passado e o presente da prática antropológica; o passado e o presente dos grupos ou sociedades que estudamos e de nós próprios como sujeitos em relação no processo de pesquisa. Trata-se também de reafirmar que, em antropologia, teoria e prática são aspectos indissociáveis quando nos propomos a construir o conhecimento. Indissociáveis são também as relações entre objeto e método, fato que incide sobre o antropólogo e o modo como ele pratica sua ciência, ou ainda, tem a ver com o como ela é praticada por outros pesquisadores em outros campos do saber.

Portanto, pensar o fazer antropológico e situá-lo no tempo e no espaço, deste ou daquele tema ou problema, exige saber e conhecer obras e trajetórias dos pesquisadores, num processo em que se confrontam os conhecimentos teóricos estabelecidos e o universo apresentado pelas culturas investigadas. Vale dizer, processo em que as teorias e as realidades empíricas constituem seu objeto singular, bem como a forma pela qual puderam tais realidades ser percebidas, contatadas e explicadas pelo antropólogo e pela antropologia através dos tempos. Formas pelas quais se constitui um "fazer-fazendo" específico na construção do conhecimento. Por esta razão, pode-se afirmar que "teoria antropológica é teoria-e-história da antropologia, da mesma forma que é teoria-e-etnografia". (Peirano, 1991, p. 46)

A etnografia, prática por excelência dos antropólogos, não é apenas uma técnica descritiva, frequentemente identificada com o trabalho de campo, a observação participante, a investigação qualitativa ou atividades concretas como as entrevistas, o questionário ou o estudo de caso, como afirmam diversos autores. Abordar a etnografia como metodologia é compreender que as técnicas de coleta de dados e outros recursos próprios desse campo encontram sua natureza e amplitude a partir de uma profunda compreensão da própria antropologia, de sua história passada e presente.

Assim, recuperar percursos e trajetórias da ciência antropológica a partir das ciências sociais torna evidente a importância da investigação etnográfica e seu papel enquanto prática. Prática que, ao se fazer-fazendo, constitui formas de saber e aprender próprias de um processo de aprendizagem inerente ao método, para além de um objeto chamado educação e de um lócus específico chamado escola. Ao mesmo tempo, permite que se admita no tocante aos fenômenos educacionais que estes não são imóveis, isolados no tempo e no espaço, como não o são os sujeitos sociais, alvo dos processos educativos. Ao se reconhecer serem eles dinâmicos, como de resto outros fenômenos sociais também o são, se aceita por desafio na antropologia e na educação o desenvolvimento de métodos de pesquisa que possam dar conta dessa dinamicidade. Aqui, entra em jogo a compreensão das técnicas de 
investigação ditas antropológicas e a noção central dessa disciplina - a noção de cultura - e suas múltiplas vertentes, como fundamentais para explicar a diversidade social humana.

No caso do campo científico moderno, entre o séc. XIX e até meados do séc. XX, prevalece uma concepção teórica centrada no "equilíbrio", da qual decorre uma concepção de educação funcional e sistêmica, mantenedora do status quo. Entre os anos 1950 e 1960 do séc. XX, irrompem-se as "teorias críticas", centradas na ideia de transformação e conflito. Neste caso, a educação assume princípios que vão de concepções de mudança, de transformação a concepções de libertação. Para cada uma delas, um arsenal teórico-metodológico se constituiu, marcando muitas das formas pelas quais a antropologia e seus métodos têm sido percebidos e compreendidos desde então. Deles depende, ainda, a maneira pela qual a antropologia e o seu fazer, a etnografia, têm abordado temas, problemas e sujeitos sociais diversos. Disso também depende o como a antropologia tem dialogado com diferentes campos do saber, entre eles, a educação. Como exemplo seguemse dois quadros parciais, sintéticos e temporalmente definidos, porém bastante elucidativos:

Quadro 1 - Antropologia e educação - 1

\begin{tabular}{|c|c|c|}
\hline & Temas & Teorias \\
\hline Final do séc. XIX & $\begin{array}{l}\text { Evolução e Progresso Cultural } \\
\text { da Infância e da Adolescência. }\end{array}$ & $\begin{array}{c}\text { EVOLUCIONISMO } \\
\text { superior/ocidental } \\
\text { etnocentrismo homogeneização }\end{array}$ \\
\hline \multicolumn{3}{|c|}{ Modelo Biológico - EDUCAC̣ÃO como ASSIMILAÇÃO } \\
\hline Início séc. XX & $\begin{array}{l}\text { Transmissão Cultural - } \\
\text { ensinamento e aprendizagem } \\
\text { Processos Inculturativos - } \\
\text { aprendizagem - personalidade }\end{array}$ & $\begin{array}{c}\text { FUNCIONALISMO } \\
\text { Difusionismo Relativismo }\end{array}$ \\
\hline \multicolumn{3}{|c|}{ EDUCAC̣ÃO como CONTROLE/SOCIALIZAC̣ÃO } \\
\hline Anos 20/50 & $\begin{array}{l}\text { Sistemas educativos Formais: } \\
\text { Instituição } \\
\begin{array}{c}\text { ANTROPOLOGIA DA EDUCAÇÃO } \\
\text { (teoria/metodologia/ } \\
\text { planejamento) }\end{array}\end{array}$ & $\begin{array}{l}\text { CULTURALISMO } \\
\text { Cult. e Personalidade }\end{array}$ \\
\hline \multicolumn{3}{|c|}{ EDUCAC̣ÃO como INTERVENC̣ÃO/HOMOGENEIZAC̣ÃO } \\
\hline
\end{tabular}




\begin{tabular}{|c|c|c|}
\hline Anos 30/40 & $\begin{array}{c}\text { Adolescência (Mead/ } \\
\text { Benedict) Vida Escolar e da } \\
\text { Comunidade Sociedades } \\
\text { Industriais (grupos. raciais, } \\
\text { sexuais étnicos, sociais } \\
\text { diferentes) }\end{array}$ & ESTUDOS DE COMUNIDADES \\
\hline \multicolumn{2}{|c|}{ EDUCAÇÃO como central p/a MUDANÇA } \\
\hline CONCEPÇÃO POSITIVISTA DE SOCIEDADE - (TEORIAS DO EQUILÍBRIO)
\end{tabular}

Quadro 2 - Antropologia e educação - 2

\begin{tabular}{|c|c|c|}
\hline & Temas & Teorias \\
\hline Anos 60/90 & $\begin{array}{c}\text { DESCOLONIZAÇÃO } \\
\text { Culturas/Subculturas } \\
\text { Interpretação/representação }\end{array}$ & $\begin{array}{c}\text { PÓS-FUNCIONALISMO } \\
\text { ESTRUTURALISMO } \\
\text { MARXISMO }\end{array}$ \\
\hline \multicolumn{3}{|c|}{$\begin{array}{l}\text { EDUCAÇÃO como REPRODUÇÃO } \\
\text { EDUCAC̣ÃO como APARELHO DE ESTADOO/ALIENAC̣ÃO }\end{array}$} \\
\hline Anos 90/2010 & $\begin{array}{l}\text { Sociedades Complexas/ } \\
\text { Antropologia Urbana } \\
\text { Processos Inculturativos - } \\
\text { aprendizagem - personalidade }\end{array}$ & $\begin{array}{c}\text { ANTROPOLOGIA } \\
\text { INTERPRETATIVA } \\
\text { ANTROPOLOGIA CRÍTICA } \\
\text { ANTROPOLOGIA REFLEXIVA }\end{array}$ \\
\hline \multicolumn{3}{|c|}{$\begin{array}{l}\text { EDUCACCÃO como TRANSFORMAÇÃO/LIBERTAÇÃO } \\
\text { (Diversidade/Campo Político de muitas possibilidades) }\end{array}$} \\
\hline \multicolumn{3}{|c|}{$\begin{array}{l}\text { TRATAMENTO COMPREENSIVO E INTERPRETATIVO DE SOCIEDADE } \\
\text { (TEORIAS DO CONFLITO) }\end{array}$} \\
\hline
\end{tabular}

Fonte: Gusmão, $2001^{4}$

Da observação desse quadro, mesmo que impreciso, resulta compreender, no movimento histórico dessa ciência, o processo de sua reformulação, criando as possibilidades de fazer a crítica sobre seus próprios caminhos e estabelecer

4. Adaptado a partir de quadro de teorias antropológicas do prof. Vagner Gonçalves da Silva (USP). 
outra forma de perceber e explicar a realidade via teorias mais compreensivas e menos positivistas. Da segunda metade do séc. XX até a presente data, as "teorias do conflito" se fazem molas propulsoras da transformação da antropologia como ciência, colocando em jogo uma perspectiva de análise, um campo ético e um campo operacional singular. Aqui a educação encontra na antropologia uma aliada, além de ser uma mais-valia para os desafios de hoje no campo educacional diante da diversidade social e cultural de grupos, povos e sociedades.

Nesta nova configuração, mantém-se a especificidade da antropologia de não opor-se a outras ciências, estar aberta ao diálogo e fundamentalmente, por meio de suas abordagens teóricas, orientar uma forma de fazer perguntas, um modo de construir estratégias próprias para investigar e buscar explicações dos fenômenos sociais. Com isso, opera-se a passagem no tempo - do passado ao presente -, a passagem de um campo a outro. Os muitos diálogos com outros saberes científicos, incluso os de senso comum, permitem construir uma perspectiva própria como ciência. 0 fato a valida e legitima de modo a configurar uma forma própria de "olhar" e "ouvir" a realidade (capacidades cognitivas fundamentais no fazer pesquisa e estabelecer os princípios do trabalho de campo, segundo Roberto Cardoso de Oliveira, 1988); uma forma específica de operar o conhecimento.

Metodologicamente, as diferentes teorias no caminho dessa ciência chamada antropologia a conduzem a desenvolver o trabalho de campo, a "observação participante" e as demais técnicas hoje conhecidas como recursos das chamadas análises qualitativas. Não se trata, porém, de um caminho linear e tranquilo - há diálogos e monólogos entre correntes teóricas; há desafios e conquistas e, ainda hoje, nos debatemos com questões cruciais quanto ao objeto e ao método singular da antropologia e de seu fazer científico.

Ainda assim, o fazer antropológico tem provocado certo encantamento e sedução no campo das demais ciências humanas. Valente (1996) afirma, em relação ao uso e abuso que se faz do fazer antropológico, que

Afinal, em que pese a aparente facilidade do emprego dos procedimentos antropológicos, sobretudo em razão da correspondência quase imediata com maneiras "familiares" de exploração do "desconhecido", acreditamos que a investigação antropológica impõe exigências que, deve-se também dizer, não são sempre atendidas ou respeitadas. (Valente, 1996, p.55)

A razão é que a adaptação por outros campos do conhecimento nem sempre leva em conta que, na antropologia, a teoria e a prática são indissociáveis, desconsideram os nexos teóricos e utilizam os recursos antropológicos apenas como técnicas aplicáveis a qualquer objeto e situação. 
Muitas vezes, esse é o caso da educação e das pesquisas educacionais que afirmam ser etnográficas. Acontece também no campo da sociologia, principalmente quando o fazer etnografia vira tão somente fazer descrição dos fenômenos sociais, armadilha e engodo de um método visto como fácil e como tal simplificado, quando usado por outros campos de saber que não buscam conhecer as matrizes teóricas que sustentam tais técnicas, os conceitos pelos quais se pautam e mesmo desconhecem as críticas da antropologia sobre si mesma.

Portanto, falar de diálogo da antropologia com outros campos do saber coloca em questão que também ocorrem monólogos - ou seja, quando a antropologia fala sozinha para si mesma, sem ter quem a ouça, ouça seus ecos, ecos de uma história singular e consistente. Outras vezes, ao se usarem as técnicas sem delas ter o conteúdo, cai-se num ritual aparente, vazio, sem qualquer consistência. Valente, já em 1996, alertava para o fato de que diferentes áreas, e entre elas a educação, desavisadamente incorporam, “sem maiores críticas, aos próprios procedimentos o método de investigação [da antropologia], arriscando-se a deformá-lo e a banalizá-lo ou agudizando os problemas" (Valente, 1996, p. 55) pela ausência da referência matricial desse campo.

Com certeza, tal questão ainda está presente neste início do século XXI, não apenas com a popularização e a "descoberta" da antropologia pela educação, senão que, também, com outros campos disciplinares que não consideram sua história, seus trajetos e suas críticas. Não consideram o movimento de uma ciência ao mesmo tempo constituída e em constituição. Sua dinamicidade faz dela - ciência antropológica - uma das chamadas ciências sociais e humanas de maior alcance explicativo desse novo século.

\section{Antropologia e educação: campo científico e poder}

Em contextosatuais, a questão que aflige o mundo moderno-aimensa diversidade social humana - exige que se pense e se redimensione o papel preponderante de uma educação que, menos positivista e mais compreensiva da realidade social, permita encaminhar problemas candentes de um mundo globalizado. Contudo, há que se superar uma visão de ação educativa, que se constitui no âmago das "teorias do equilíbrio", e colocar em movimento a multiplicidade de caminhos possíveis do campo educacional no interior das chamadas "teorias do conflito" e de outras teorias ainda em constituição.

Assim, pensar as possibilidades explicativas da antropologia é ter que reconhecer que se trata de uma ciência muitas vezes contraditória em seus princípios. Contradição que tem seu embate em termos de um campo teórico 
sobejamente criticado que está na base de sua conformação como ciência, ao mesmo tempo que o próprio campo aponta para o novo tempo, em que o conflito permeia as possibilidades de sua maior ferramenta - a noção de cultura - não ser reduzida, tão somente, ao campo simbólico que a representa. Aqui, cultura é, antes de qualquer coisa, mediação. Parte de um campo científico e político que não pode ser negado. Gusmão (2010, p. 263, nota 2) afirma:

As culturas como práticas simbólicas e estruturas de mediação constituem um campo político de muitas possibilidades, já que envolvem seletividade, ideologia e mudança; envolvem o espaço político das relações entre os homens, implicando relações de poder vigentes para cada grupo e sociedade, embora não se confundam com esses processos. Por tudo isso, pode-se afirmar a impossibilidade de definir, de um modo único e total, um conceito de cultura, principalmente ao se tratar de sociedades complexas.

Dessa concepção de cultura, resulta a importância de conhecer as teorias datadas historicamente para superar o senso comum que, na adaptação/passagem e uso dessa noção, entre um campo de saber e outro, acabou por fragilizar essa ferramenta de explicação das sociedades humanas. Tal conceito ora é transformado em conceito mágico que explica tudo, ora banalizado e reduzido a traços culturais e diferença - de modo a completar o processo de redução da antropologia de ciência explicativa e crítica a ciência meramente descritiva e tudo o mais que isso significa. Aqui também, encontram-se um dos receios dos antropólogos quanto à popularidade de seu campo e explosão de pesquisa ditas "etnográficas".

Do passado ao presente da prática antropológica, está em questão, de modo permanente, o que se entende por cultura. A variabilidade do conceito, suas múltiplas definições e os usos que delas decorrem não são fruto do acaso, mas de igual modo correspondem a campos de interesse postos em movimento pelo contexto histórico, social e político e suas demandas.

A título de exemplo, lembro aqui a importância dessa noção para a realidade europeia, que vem sendo tratada, em análises acadêmicas, pelos mass media e pelo senso comum, de modo a explicar, em diferentes níveis, a presença estrangeira, em particular o caso dos imigrantes extracomunitários. Henrique Santamaria, da Universidade de Barcelona, declara constituir um dos fenômenos fundamentais de nosso tempo, a gênese da cultura, como noção-chave nos meios de controle e de gestão social das populações. Ou seja, a noção de cultura ocupa um lugar central nas sociedades contemporâneas a ponto de sustentar que hoje estão nascendo sociedades multiculturais (caso de Portugal), como se nunca tivesse existido diversidade no seio das sociedades agora ditas multiculturais, localizando aí, da noite para o dia, as causas dos conflitos entre grupos, principalmente grupos 
étnicos de que fazem parte os imigrantes extracomunitários no mundo europeu. Tal discurso assimila a sociedade à cultura e assim oculta, relega, quando não deprecia as dimensões econômicas, políticas e propriamente sociais que também configuram as dinâmicas e os conflitos sociais (Santamaria, 1998, p.62). E pode fazê-lo, porque, entre outros fatos, diz o autor, a cultura hoje sofre um processo de entronização cultural, que Verena Stolcke, denomina como "fundamentalismo cultural". Trata-se de um processo que faz da cultura a única dimensão explicativa dos comportamentos dos outros, que, embora postule o respeito e o valor da diversidade cultural, destaca a incomensurabilidade das diferentes culturas coisificando-as. E o faz porque concebe a cultura como um conjunto de normas, valores e tradições, conjuntos compactos, fechado, harmonioso e dado, do qual os indivíduos seriam meros portadores ou instrumentos. As diferenças culturais convertem-se assim, diz ela, em eficaz recurso de legitimação, na melhor demonstração de naturalização das profundas desigualdades sociais e políticas que percorrem as sociedades contemporâneas.

0 que esse exemplo quer dizer?

Que o uso da noção de cultura muitas vezes desconhece a dimensão política do conceito. Desconhece que os fatos sociais e o campo político em que estes se inserem envolvem a realidade da vida social e seus contextos, uma vez mais retirando do âmbito da cultura a sua condição de mediação, desde muito defendida pela antropologia. Como diz Kuper (2002), a cultura desde sempre foi uma questão política. Com isso pode-se dizer que a antropologia não se resume a ser uma ciência da tradução do mundo, como também não é apenas um conjunto de técnicas etnográficas. E não o é, antes de tudo, porque seu fazer não é neutro, como não são neutros os conceitos e instrumentais que usa.

Torna-se necessário que se pensem os fatores econômicos, o contexto político, a sociedade global, o interno e o externo em termos políticos e práticos, para que as certezas e naturalizações das ações humanas possam se quebrar. Com elas, desconstruímos as pré-noções e preconceitos, garantindo a possibilidade de apreender a realidade social em nova dimensão ou, ainda, em dimensões alternativas ao que é social e ideologicamente pressuposto.

Não levar em conta todas as questões envolvidas, de modo informado e consistente, acreditando que etnografia é descrição, sem questionar o que se descreve, como e por que, sem questionar o que se olha e se ouve, resulta no que depois produzimos como textos falados ou escritos, e perdemos de vista as possibilidades de uma ciência crítica que a antropologia foi, é e pode ser.

Desencontros e desconhecimentos do campo antropológico na adaptação e passagem para outros campos do saber - sua generalização e popularidade - dá a nós, antropólogos, muito orgulho, mas também muita apreensão. A grande questão 
é o desconhecimento do campo de tensão que orienta o olhar de quem olha; é o deixar de atentar para o modo pelo qual olhamos, percebemos e explicamos uma dada realidade que envolve nossa maneira de ser, nosso mundo e a maneira de ser do outro e de seu mundo. Desconhecer a teoria que informa nosso olhar e que antropologicamente não pode ser esquecida coloca em risco as possibilidades de uma visão abrangente e crítica da realidade.

Este outro olhar, que evoca o uso da etnografia dentro do campo da educação ou outro qualquer, não pode reduzir essa ciência a uma técnica. Deve-se "tratála como uma opção teórico-metodológica, (...) [que] implica conceber a prática e a descrição etnográficas ancoradas nas perguntas provenientes da teoria antropológica" (Gusmão, 1997, p.41). Assim, não basta ir a campo, não basta o trabalho empírico, a observação participante, o uso de entrevistas ou quaisquer outros recursos, se não se considera o ângulo do qual se parte e se adota para examinar a realidade; se não se consideram o modo de ser que nos envolve, a nossa vivência imediata - nosso cotidiano - e o cotidiano da pesquisa, o ordenamento simbólico que nos orienta em termos de um saber de senso comum - um saber teoricamente informado que resulta na construção de um saber sobre o outro e um saber sobre nós mesmos; experiência vital de tempo e espaço, de si mesmo e do outro que nos fala da vida social, não pelo que nos é dado a ver senão que descobrir para refletir com ela e sobre ela. Aqui a antropologia e a sua prática como etnografia faz sentido e tem muito a dizer, tanto para o universo acadêmico e científico, como para o universo de demandas e de lutas sociais que envolvem grupos, segmentos de grupos e o próprio Estado-nação com suas leis e decretos.

\section{Antropologia e educação: 0 caso brasileiro ${ }^{5}$}

Ao finalizar o debate aqui proposto, retomo contribuição que fiz em coletânea organizada por Sandra P. Tosta e Gilmar Rocha (Gusmão, 2014), em vias de ser publicada, que sintetiza o debate em torno de uma antropologia da educação. Em sua proposta, os autores afirmam que a antropologia da educação na América Latina e no Brasil se faz em torno de dois pontos convergentes: 1) a "importância da etnografia", não só como instrumento metodológico, mas como "um profundo e significativo processo de reflexão epistemológica" a produzir conhecimento; 2) o "papel da história" na compreensão das relações entre antropologia e educação e a dimensão política dessa relação.

5. Apresento aqui algumas ideias expostas em entrevista concedida a Amurabi de Oliveira, publicada na revista Cadernos de Campo, USP (2013) e, também, reproduzo algumas ideias de texto a ser publicado em coletânea organizada por Sandra Tosta e Gilmar Rocha que se encontra no prelo. 
Além desses pontos fundamentais expressos nos itens anteriores já discutidos neste texto, cabe destacar que a abordagem da educação pela antropologia, que aqui defendo, tem a ver com questões relativas ao método e objeto(s) do campo antropológico. Contudo, não se limita a isso, pois se encontra centrada em processos educativos para além da escola, evidenciando as múltiplas possibilidades da etnografia como método científico aberto a vários domínios da vida social. Assim, a etnografia se faz "um lugar de fronteira", tal como afirma Ricardo Vieira, autor português, em diferentes textos a respeito do tema. Fronteira essa que encontra na noção de cultura seu centro multifacetado pelos contextos simbólicos e socioculturais, incidindo no uso do método etnográfico em contextos educativos. Nesse sentido, esta proposta ultrapassa visões fechadas da educação, como escolarizada e reprodutivista, ao mesmo tempo que busca defender uma "etnografia da educação”, de caráter interpretativista e semiológico, espaço de conformação de uma "antropologia da educação" no caso brasileiro. Trata-se de construir uma abordagem que toma por base as ciências sociais para falar em educação. Entende-se aqui a necessidade de compreender o significado da etnografia não só como método, mas, também, como epistemologia geradora de conhecimento.

A proposta é, então, a discussão do aparato teórico, de modo consistente, para embasar os estudos etnográficos na antropologia, definir a natureza do trabalho de campo e, também, estabelecer parâmetros na análise dos fenômenos educativos. Aqui, a ausência ou escassez na tradição de estudos antropológicos com o tema educação no caso brasileiro talvez sejam algo a ser considerado.

Na verdade, no Brasil, na primeira metade do séc. XX, mais que a antropologia, foi a sociologia que olhou mais detidamente a educação. A razão está em que, nesse período, sob a égide do positivismo, das "teorias do equilíbrio", a antropologia que se constituiu no Brasil assumiu um cariz cultural, fato que leva posteriormente à negação da educação como objeto de interesse por parte dos antropólogos. A antropologia mais crítica que emerge nos anos de 1950 gradualmente "esquece" a educação e deixa de vê-la como um campo político de muitas possibilidades. Contudo, em um contínuo temporal bastante demarcado, pode-se situar o interesse por estudos mais qualitativos, nos quais a etnografia passa a ser importante quando o tema é educação. Trata-se da segunda metade do séc. XX, mais nomeadamente dos anos de 1970/80 em diante. Época política intensa que, em toda a América Latina, incluso o Brasil, é marcada por ditaduras e movimentos sociais emergentes que obrigam uma retomada de valores e de posicionamentos sociais e políticos. 0 mesmo acontece no mundo acadêmico, da segunda metade do séc. XX em diante, em relação à educação e a muitos outros temas antes tidos como secundários ou menores lquestão étnica, de gênero, 
por exemplo). Esse contexto possibilita a emergência de diferentes propostas com relação à educação e, no caso particular do Brasil, à constituição de uma antropologia da educação que só começa a tomar fôlego ao final do século em tela, dos anos de 1990 em diante.

Daí que, no Brasil, a fraca presença de estudos antropológicos com a temática da educação (com exceção da educação indígena) e a ausência de formação com o tema nos cursos de ciências sociais, particularmente na antropologia, enfraquece os contornos de uma "etnografia da educação". Razão, talvez, das dificuldades nos estudos brasileiros com a educação e com o método etnográfico no campo da educação, já bastante criticado por diferentes autores (Gusmão, 1997; 2003; Valente, 1996; 1997; entre outros) que não tratamos aqui, por centrarmos o olhar nas ciências sociais. Hoje, a existência de certo mascaramento da questão na antropologia exige rever não um, mas vários momentos seminais da antropologia que se pratica no Brasil. Isso importa para demarcar e compreender as razões dos limites em torno do tema "educação" em nossas pesquisas e o reflexo disso em termos da constituição de um campo de interesse denominado antropologia da educação.

As possibilidades de uma antropologia da educação moderna e crítica, no caso brasileiro, estão postas no cenário acadêmico e científico. Cabe a nós compreender os muitos caminhos de um saber de fronteira e, assim, empreender diferentes trajetórias etnográficas para dar corpo e alma a uma antropologia da educação que tenha em conta o ofício etnográfico na dimensão de um campo científico competente para não cair em idealismos relativistas e vazios. Adaptando as palavras de Kuper (2002) ao que aqui se discute, não cabe a nós antropólogos "desviar a atenção do que temos em comum" - a antropologia e a educação. 0 que nos cabe é estimular o debate para além das fronteiras, sair da zona de conforto representada pelo que nos é próximo, reconhecido e legitimado para constituir outros horizontes.

\section{Referências}

FONSECA, Claudia. Quando cada caso NÃO é um caso. Revista Brasileira de Educação. n. 10. jan/fev/abr. 1999 pp. 58-78.

GUSMÃO, Neusa Maria Mendes de. Antropologia e educação: origens de um diálogo. IN: GUSMÃO, Neusa Maria Mendes de. Antropologia e educação. Interfaces do ensino e da pesquisa. Cadernos CEDES, n. 43, Campinas: Centro de Estudos Educação e Sociedade/ UNICAMP, 1997 pp. 8-25.

GUSMÃO, Neusa Maria Mendes de. (Org.) Diversidade, cultura e educação: olhares 
cruzados. São Paulo: Biruta, 2003.

GUSMÃo, Neusa Maria Mendes de. Por uma antropologia da educação no Brasil. ProPosições. Revista da Faculdade de Educação/UNICAMP, v. 21, n. 2 (62) - maio/ago. 2010. pp. 259-265.

GUSMÃO, Neusa Maria Mendes de. Aportes finais de um debate em aberto. In: TOSTA, Sandra P; ROCHA, Gilmar. Diálogos sem fronteira. Historiografia, etnografia e educação em culturas ibero-americanas. Belo Horizonte: Editora Autêntica, 2014. No prelo.

KUPER, Adam. Cultura. A visão dos antropólogos. Bauru, SP: EDUSC, 2002.

LAPLANTINE, François. Aprender antropologia. São Paulo: Brasiliense, 2007. $20^{a}$ reimpr. (1a ed. de 1988).

LOVISOLO, Hugo. Antropologia e educação na sociedade complexa. Revista Brasileira de Estudos Pedagógicos. n. 65, jan./abr. de 1984, pp. 56-69.

SANTAMARIA, Enrique. Do conhecimento de próprios e estranhos (disquisições sociológicas). In: LARROSA, Jorge; LARA, Nuria Pérez de. (orgs.) Imagens do outro. Petrópolis :Vozes, 1998. pp. 47-66.

OLIVEIRA, Amurabi. Antropologia e/da educação no Brasil: entrevista com Neusa Gusmão. Cadernos de Campo. n² 22, jan./dez.(2013). pp. 147-160. Disponível em: <http:// www.revistas.usp.br/cadernosdecampo/article/view/56167>. Acesso em: 10/05/2014 OLIVEIRA, Roberto Cardoso de. Ao trabalho do antropólogo: olhar, ouvir, escrever. In: OLIVEIRA, Roberto Cardoso de. 0 trabalho do antropólogo. Brasília: Paralelo 15; S Paulo: Ed. UNESP, 1998. pp. 17-35.

PEIRANO, Marisa. Os antropólogos e suas linhagens. Revista Brasileira de Ciências Sociais. n.16, ano 6, jul. de 1991 pp. 43-50.

SANCHIS, Pierre. Uma leitura dos textos da mesa redonda sobre ensino de ciências sociais em questão: a Antropologia. In: GROSSI, Mirian P.; TASSINARI, Antonella; RIAL, Carmen (Orgs.). Ensino de antropologia no Brasil: formação, práticas disciplinares e além fronteiras. Blumenau: Nova Letra, 2006. pp. 111-125.

TOSTA, Sandra P.; ROCHA, Gilmar. Antropologia \& educação. Belo Horizonte: Autêntica, 2009.

VALENTE, Ana Lucia E. Farah. Usos e abusos da Antropologia na pesquisa educacional Pro-Posições.- Revista da Faculdade de Educação/UNICAMP, v. 7, n.2, jul. de 1996. pp.54-64.

VALENTE, Ana Lucia E. Farah, Por uma antropologia de alcance universal. Cadernos Cedes 43. Campinas:Centro de Estudos Educação e Sociedade - Cedes, 1997. pp. 58-74. VIEIRA, Ricardo. Mentalidades, escola e pedagogia intercultural. Educação, Sociedade \& Culturas, n.4, 1995.

VIEIRA, Ricardo. Histórias de vida e identidades. Professores e interculturalidade. Porto: Afrontamento, 1999. 
Recebido em junho de 2014

Aprovado novembro de 2014

Neusa M. M. de Gusmão é doutora em antropologia social pela Universidade de São Paulo (USP), professora titular do Departamento de Ciências Sociais na Educação da Faculdade de Educação da Universidade Estadual de Campinas (UNICAMP). E-mail: neusagusmaoduol.com.br. 